
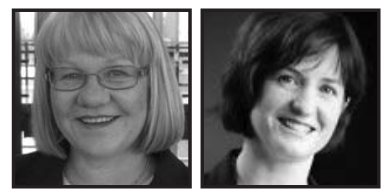

\title{
Owning Our Learning: Scaffolding Professional Inquiry for Educators
}

\author{
Willow Brown, University of Northern British Columbia \\ Sabre Cherkowski, University of British Columbia Okanagan
}

\section{ABSTRACT}

The authors advocate professional inquiry as purposeful, site-based learning for teacher leaders and school administrators. A key argument, social symmetry, proposes that creating engaged, inquiring learners requires teachers to own their learning through professional inquiry. A four-meeting model scaffolds collaborative inquiry from problem framing, through experimentation, and toward new convictions and commitments. The design of this professional inquiry platform has been informed by action research and school improvement and inspired by $21^{\text {st }}$ Century Learning.

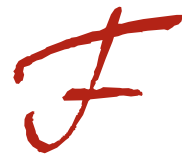

ormative assessment experts have advocated a series of instructional innovations, from clear learning intentions and criteria to descriptive feedback and goal setting, all aimed at developing students who own their learning (Kaser \& Halbert, NPBS website, n.d.; Black \& Wiliam, 1998). Learners who have achieved the ultimate goal, a sense of ownership, understand their unique strengths and needs and routinely identify personalized goals. Familiar with inquiry processes, these students can frame and pursue personally meaningful topics of investigation and share their discoveries in their own confident voice (Brown, Klein, \& Lapadat, 2009). They know what they want to work on next and their learning has been energized by the ability to make these choices. Recent case studies have established that developing school-wide student ownership of learning in an elementary school is indeed possible and of great benefit to the young learners (Koehn, 2011). 
However, in our experience as teacher educators and school improvement researchers, schools where a majority of students own their learning are rare. To bring about this kind of energized learning on a broad scale, we have contributed our efforts to the formative assessment movement that we believe has great potential for creating schools that are sustainable learning communities for both children and adults (Mitchell \& Sackney, 2009), specifically through the British Columbia Network of Performance Based Schools (NPBS). Our learning partners in this Network are teacher leaders who have learned to create the conditions for student ownership by following a progression of six important strategies (Kaser \& Halbert, NPBS website, n.d.; Black and Wiliam, 1998). They began by setting clear learning intentions and generating criteria with their students. After learning to provide feedback based on criteria, they branched naturally into routinely setting personalized goals with students and inviting students to shape their own inquiries. However, we also know of teachers who share their intentions and criteria with students but have not progressed toward developing student ownership of learning. As student inquiry gains significance as an instructional strategy (Alberta Learning, 2004), we believe that most teachers have had little experience with the kind of energizing and meaningful learning opportunities they are charged with creating for students. If we are to achieve widespread improvement in student achievement through increasing student ownership of their learning, we must pay attention to the conditions that create this sense of ownership of inquiry among teachers.

We have observed that teachers who are successful at moving toward student ownership of learning are inquirers themselves-constantly curious and empowered to ask questions as well as seek and share answers applicable to their practice. The watershed between teacher-directed and student-owned learning appears to lie between setting clear intentions for students and leading students to share in the design of learning that is both personally meaningful and connected to the curriculum. In this paper, we propose that an orientation to inquiry is a crucial ingredient for a shift toward ownership of learning, both in the teachers' experience and mental models and for students in the classroom. Teachers who "own their learning" engage in a continuous process of reflecting on their strengths as well as their needs to be able to identify their own personalized learning goals. In this spirit of inquiry, they pursue personally meaningful topics of investigation and share their discoveries in their own voice. The cycle of inquiry continues as they make meaningful choices about setting further learning goals. To facilitate this inquiry process, we provide a four-meeting platform, or scaffold, to support initial experiences with collaborative professional inquiry. Our model is a learning-oriented design situated within the field of school improvement and informed but not limited by action research 
traditions. Focusing on professional inquiry and teachers owning their learning provides a fresh conceptualization of action research, a premise we develop more fully in a later section of this paper. Beyond the notion of social symmetry, a name that we have applied to a frequently mentioned phenomenon, our model is founded on three classic school improvement themes: a) creative tension (Lewin, as cited in Senge et al., 2000), b) single and double loop learning (Argyris \& Schon, 1978), and c) the need for new beliefs to sustain new practices (Fullan, 2007).

\section{Our Central Argument: Social Symmetry}

Our central argument hinges on a common assumption in school improvement literature: it is difficult for teachers to create, for their students, experiences and social conditions they have not experienced for themselves. In the literature we reviewed for our studies of the development of professional learning communities, we encountered this phenomenon so frequently that we termed it social symmetry (Brown, 2004). Sarason (as cited in Mitchell \& Sackney, 2009) described the phenomenon as a mirroring process in which teachers tend to view students the way administrators regard them, to anchor "traditional power dynamics across the system and perpetuate them in classrooms" (p. 150) and thus inhibit change. Mitchell and Sackney (2009) emphasized the notion as part of the reciprocity characteristic of living systems:"we return to one another the kinds of behavior that we receive" (p. 184). In our school improvement work and university teaching, the notion of social symmetry has helped us strive to create, for pre-service teachers and educators enrolled in master's programs in leadership, the kinds of experiences, relationships, and social conditions we hope they will create for their students. Our capacity-building purpose leads naturally to an emphasis on inquiry as a learning process that values the interests of learners and enables them to seek, synthesize and share meaningful information. Thus, the notion of social symmetry supports our interest in establishing inquiry as a characteristic of professional culture, both to energize educators for their own benefit and to build their capacity to create life-enhancing learning experiences for students. 


\section{More on Our Sustainable Professional Learning Community Framework}

Our vision of ideal learning experiences and social conditions draws on Mitchell and Sackney's (2000, 2009) sustainable professional learning community research and theory. For these authors, interdependence, a key aspect of high-capacity schools, has grown from systems thinking (Senge, 2007) to an ecological model of life-enhancing schools that use "the power of meaning and purpose to align activities and to cohere practices" (Capra, as cited in Mitchell \& Sackney, 2009, p. 178). As an ideal created from a composite of case studies, sustainable learning communities are filled with new life and energy as a result of a profound shift in thinking about learning. “Deep learning” (Mitchell \& Sackney, 2009, p. 185) legitimizes knowledge through authentic, context-specific inquiry rather than through pre-determined standardization: prior knowledge of learners is respected and pathways to learning are not as controlled and limited, either by policy and top-down directives for educators or by provincial curriculums and teacher preferences for students. In an atmosphere of trust, both young and adult learners engage willingly in inquiries that address their own compelling questions and generate creative responses to real problems. Beyond this significant perspective of learning as authentic inquiry, the learning community framework has provided key words that capture the characteristics of a sustainable learning community: Wholeness, Awareness, Meaning, and Commitment. We have used these words to describe the phases of inquiry in our scaffolding model, thus enriching the traditional action research sequence of plan, do, reflect, and revise (Carr \& Kemmis, 1986; Reason \& Bradbury, 2008), with the understandings of change implementation and teacher/administrator learning we have drawn from school improvement research.

\section{Origins of Our Professional Inquiry Platform}

Our four-meeting inquiry model is a scaffold, or platform, to support teachers who are new to collaborative inquiry or to facilitating an inquiry process with colleagues. This model was developed in response to an authentic problem: teachers, administrators, and a researcher in an inner-city school in Saskatchewan (Brown, 2004) wanted to collaborate purposefully in a shared inquiry but needed a common language and clear process to support their journey toward learning community capacities. Since that time, we have applied and refined the model in collaborations with educators in the Yukon and in British Columbia, including: a) northern K-12, 
post-secondary, and community educators seeking to erase racism in their practice, b) secondary teachers developing a scope and sequence to improve delivery of their mathematics curriculum, c) learning support teachers and their district leaders investigating the implications of a shift in their role from student pull-out to teacher support, and d) elementary and secondary principals inquiring as to how to lead for improved student literacy. Graduate students have also adapted the model to their own inquiries, as in Andrea Davy's study of the development of democratic discourse in a primary classroom (Davy \& Brown, 2007) and in Jodie Baker's current collaboration with teachers for reflective implementation of a student inquiry platform.

We have facilitated a walk-through or simulation for our model at workshops for K-12 and post-secondary educators (Brown, 2007) and a recent version of the handout is available on a website that we have set up to support our research on multimodal literacy (Brown \& Lapadat, n.d.). The handout posted on this site was designed to support school-based facilitators with guiding questions for each of the four phases of a collaborative inquiry as well as formats for five-minute journals (Philips, 1996) for participants to record observations between meetings. Supporting our definition of a learning platform as a document or template that scaffolds new instructional behaviours and helps develop the beliefs that will sustain those practices, we have termed this process, as supported by the handout as template, a professional inquiry platform.

\section{Inspiring Literature}

In addition to refinements to the process emerging from each project, we have developed our understanding of professional inquiry by synthesizing new reading with our existing framework, notably Timperley's (2005) analysis of effective forms of teacher learning, and Hattie's (2008) analysis of 205 studies of Enquiry-Based Learning (EBL), which established that student engagement in inquiry consistently produces transferable critical thinking skills, improved achievement, and improved attitude toward the subject. Hannon and Mackay (2010) have helped us link our work on student inquiry (Brown, Klein, \& Lapadat, 2009) and professional inquiry, which may include any adult in the school, to principles of $21^{\text {st }}$ century learning. To increase use of inquiry as an instructional strategy, Hannon and Mackay highlighted the following characteristics: inquiry is most effective when it is purposeful, or emerging from real community need; when it is project-based, when it is publicly presented, and most importantly to our platform approach, when it is scaffolded. 
Recently, we have been inspired by the Learning Futures project, which has included over forty schools in England. In this school reform initiative, student inquiry is a key component: "how students learn is as important as what they learn, because learning is a skill they can carry with them for their entire lives" (Paul Hamlyn Foundation, Ideas page). "Students become 'expert learners' by learning through enquiry — formulating questions, researching, and experimenting" (Paul Hamlyn Foundation, Enquiry-Based Learning page), in contrast to transmissive learning, which develops a more narrow skill set based on listening, memorizing, and repeating. In a downloadable pamphlet that presents emerging findings on engagement, these researchers have proposed, as we do in this paper, that what schools need to do in order to increase authentic student engagement "is to become themselves more engaged - as learning communities, in learning outside school, in partnership with local communities and parents" (Paul Hamlyn Foundation, News page). We see the patterns of deep engagement that are emerging in the Learning Futures study, findings that deeply engaged learning is placed, principled, purposeful, and prolonged (Paul Hamlyn Foundation, About page), as contributing to a set of criteria by which we can consider deep engagement for educators, assessing and adjusting our professional learning platform design as well as self-regulating specific projects as they unfold.

Timperley's (2005) analysis of effective forms of teacher learning has suggested additional criteria for assessing the effectiveness of learning-oriented designs (Kaser \& Halbert, 2009). Above all, Timperley has asserted that successful inquiry is evidence-based and focused on student outcomes, which we agree is the central purpose of schooling. Successful inquiry also serves a self-regulatory function for teachers and its theoretical understandings must have coherence with other initiatives, beliefs, practices, and values. Finally, successful inquiry results in subjective meanings or internal commitments that are derived from experiential evidence. To summarize Timperley's points, at the end of a successful inquiry, educators have made specific changes to practice that have demonstrated effectiveness for student outcomes and will be sustained through integrated skills, understandings, and values. We believe our professional inquiry platform has successfully met many of these requirements, with variation from project to project. 


\section{Professional Inquiry Platform Projects: Collaboration and Focus}

Although the professional learning community (PLC) literature commonly refers to collaborative inquiry into student learning as a central process (Dufour \& Eaker, 1998; Mitchell \& Sackney, 2000), little is mentioned about precisely how to craft inquiry questions or structure meetings. A lack of focus and ineffective use of collaborative time is a common complaint when PLC implementation is not perceived to be effective. This platform may provide the support that is needed. We believe the process is best learned in an apprenticeship or workshop simulation, where participants in learning teams led by a skilled facilitator gain the experience to lead a learning team in their own workplace.

We encourage collaborative inquiry shared by teachers and administrators, if possible, acknowledging Robinson's (2008) finding that the single most effective instructional leadership behavior is participation in professional learning with teachers. Professional inquiry may be conducted by groups of teachers focused on problems or opportunities related to a specific grade or subject area, as in the secondary math inquiry, or questions spanning grades and subjects and even types of educational institutions, such as in the Yukon's Erasing Racism project. There are also times for independent inquiry. However, in the learning-oriented design of our inquiry platform, we aspire to make personal learning accessible to the group (Mitchell \& Sackney, 2000) in order to build overall cultures of inquiry. Thus we encourage discussion of insights and findings with mentors or colleagues wherever possible.

To hold the attention of educators and to have lasting impact in practice, the focus of professional inquiry must be manageable within the context of busy lives and yet have meaning beyond the trivial. Our solution has been to draft a common umbrella question that unites the diverse interests of a group but allows each participant the latitude to focus on a specific, meaningful aspect of the inquiry. For instance, when principals in central British Columbia investigated literacy leadership, some chose to inquire into how to develop a school-wide sense of belonging to support learning and others moved directly to sharing reading comprehension strategies with teachers. The umbrella question gave the inquiry team a common purpose, making their discoveries relevant and their suggestions useful to each other.

An on-site facilitator may choose an inquiry topic, frame it as a question, and invite colleagues with similar interests to participate. Alternately, a learning team may 
develop a common focus together. Groups may be any size but three to six members allows each member to participate actively and brings a variety of approaches that enriches learning from each other as well as from personal experimentation. In our largest groups, such as the learning support teacher project that we conducted at the school district level with more than twenty participants, shared sessions consisted of whole group planning interspersed with small group discussion, and most team members led a school-based inquiry cycle between meetings.

For an initial inquiry with an inexperienced team or facilitator, we recommend just four meetings of not more than ninety minutes, spaced evenly throughout a term to allow practice-based experimentation between meetings. For ongoing commitment to the process, it is important to avoid busy times such as start-up, reporting periods, and yearend. We have incorporated Sagor's (2000) advice on setting ground rules, inviting participants to make consistent attendance and participation a priority. However, in the interest of capacity-building, we have routinely allowed group membership to remain open, so that if the ongoing inquiry attracts the interest of new participants, they can be included from that point. We have also expanded a study beyond four meetings: experience with the process has made it evident that additional meetings at any phase could serve the unique interests and energies of a specific group.

\section{The Professional Inquiry Platform}

To make Mitchell and Sackney's (2000) learning community theory accessible to teachers, Brown (2004) designed a poster and a mural to present an image of a strong and interdependent learning community, a learning or giving tree (Silverstein, 1964), responsive to the shifting needs of students, families, and neighbourhoods. Rooted in principles of wholeness, awareness, meaning, and commitment, this image emphasized simultaneous learning at personal, interpersonal, and organizational levels, as symbolized in the leaves, the flowers and fruit, and the trunk and branches of a mature and productive tree capable of nourishing other life. As the collaboration unfolded, the four principles of a learning community, presented graphically in a circle around the tree figure, came to be used to describe the phases of inquiry that move learning teams toward learning community development, replacing and enriching the plan, do, reflect, and revise cycle common in action research. Here we outline the four phases of a professional learning platform, which are not intended to be rigidly sequential, and describe the guiding questions that help new 
facilitators keep learning community principles alive in participants' developing beliefs and practices.

\section{Wholeness}

When an inquiry or learning team has formed and gathered for their first meeting, we invite participants to focus on a catalyst reading, presentation, or workshop. This catalyst expands a whole team vision of what is possible and is the foundation of creative tension (Lewin, as cited in Senge et al., 2000), which energizes incremental steps toward the vision. We encourage team members to think of wholeness as a systems view in which all initiatives and responses are interconnected, so that change in one area may create unanticipated changes or tensions in others. In the Wholeness phase of inquiry, we have found it essential to create or review a collective vision of the ideal world the team wishes to create, through this and subsequent inquiries and other activities. A more practical next step is to generate, from the catalyst and from collective experience, a list of strategies that have potential to bring the vision to reality in classrooms and throughout the school.

An important aspect of the wholeness principle is uniting the group under a common umbrella question and valuing the contribution of each member, through the exploration of personal questions, to a holistic or gestalt-like group understanding. When common ground has been established, diversity of perspectives is appreciated as having potential to contribute to the learning of all participants. Freedom of choice within the overall topic allows participants to see their own inquiry as directly relevant to their work. As for student inquiry, choice appears to bring energy for learning and to energize the classroom or school-based experimentation that will contribute to the richness of reflection.

To summarize, a sense of purpose is established in this first phase of inquiry as creative tension, a clearly articulated difference between the real and the ideal, energizes the team to work toward a range of solutions for an immediate problem or to access a new opportunity. At this meeting, guiding questions build a sense of coherence between this inquiry and other initiatives, to combat the fragmentation that is a common enemy of school change (Fullan, 2007) and to build the coherence among innovations recommended by Timperley (2005).

Until the second meeting, participants are encouraged to make focused observations and record key words and phrases daily in a structured five-minute journal. The creative tension journal format helps build awareness of the difference 
between current and desired practices and between current and desired student responses. We make it clear to participants that the small notebook we provide for their journal is their own property and will not be reviewed by anyone. The intended function of the journal is to jog participants' memories about strategies they have tried and specific student responses, to enrich dialogue with colleagues at the next inquiry meeting. However, we have also found that the physical presence of the journals reminds participants to find time most days to focus their thoughts on our collaborative project. When little or nothing has been written in the journal, as frequently happens, participants seem to have specific observations to contribute because of mental notes they have made with the intention of writing them later. Although we believe that short, frequent periods of written data collection are most effective, we appreciate all efforts and acknowledge that mental notes also contribute to collaborative reflection and to learning.

\section{Awareness}

Awareness is the focus of the second meeting, although developing keener awareness of the difference between the real and the ideal and data-informed awareness of the impact of actions are twin awareness themes that run through all phases of an inquiry. At this second meeting, facilitators invite participants to share insights from the creative tension journals they have been keeping, or intending to keep, since the last meeting. Regular references to the wholeness vision that was shared at the first meeting occurs as each participant identifies a specific strategy he or she will experiment with to try to bring the current situation closer to the ideal. Colleagues help each other to identify the precise classroom observations to be made or information to be gathered, in order to assess the effectiveness of the target strategy in terms of student response. Problems with implementation are anticipated and solutions brainstormed in advance, which becomes simpler when two or more participants choose to focus on a similar strategy.

The second session concludes with a review of how participants believe they are moving toward the overall wholeness vision or some aspect of it, to provide a sense of momentum or what Kotter and Cohen (2002) have called short-term wins. Until the next meeting, the action step journal format encourages participants to record the specific strategies they try and the student responses they observe, as well as subsequent adjustments to the strategy before the next round of observations. It is also made clear that participants are free to abandon and replace strategies when problems of implementation appear, for the time being, insurmountable or not currently worth the time and effort to redesign them. Although most participants 
initially choose strategies that can be adapted over time to a specific group of students or teachers, alternate strategies are readily available as a result of discussing approaches chosen by other team members.

\section{Meaning}

The third meeting focuses on developing personal meaning from cycles of action, observation, and reflection. Inquiry team members begin to talk about how they have been integrating their experience-based beliefs with the perspectives expressed in the catalyst article and other readings, as well as with insights from colleagues. At this point, the classic notion of single and double loop learning (Argyris \& Schon, 1978) comes into play, as valid single loop learning occurs when new skills and practices are developed, congruent with existing beliefs. For example, most of the participants in the Erasing Racism group did not change their belief in anti-racist education but they did come to a fuller understanding as to how discourse patterns in classrooms could be altered to help Aboriginal students experience less alienation. Less frequently, double loop learning occurs when core beliefs, assumptions, or mental models (Senge, 2007) are challenged by careful observation and discussion of student responses and beliefs begin to shift in a more transformative way. An example of double loop learning occurred in the secondary Math Scope and Sequence study, when teachers with only one or two courses in Math came to value collaboration as a culturally accepted way to access the experience of an entire department for the benefit of their students. Although the senior teachers and learning team leaders envisioned this orientation to collaboration as an outcome of inquiry, collaborative redesign of curriculum based on a shared understanding of student needs was a transformative experience for younger team members.

In the Meaning meeting, guiding questions alert the team to watch for surprises or anomalies in student responses. They are encouraged to reflect on beliefs that are not congruent with what they have seen and to consider alternate ways of thinking, which are often evident in a diverse group or can be suggested by the facilitator in light of readings. Participants are invited to begin to make value judgments about the strategies they have tried and the effects of these strategies, in preparation for commitments to all or parts of the new beliefs and practices. Until the final meeting, experimentation continues and the action step journals are used to note and reflect on reasons for decision points, the junctures at which strategies have been adjusted or replaced. Before the fourth and final meeting, participants think carefully about their developing convictions, the strong beliefs that integrate the research and professional literature with well-considered experience. They prepare to articulate commitments to practices that are more fully congruent with their convictions. 


\section{Commitments and Celebration of Learning}

The fourth and final meeting is a time to articulate commitments to learning team members and to oneself, to articulate how each person believes his or her practice will be forever changed, even slightly, as a result of new beliefs and strategies developed in the inquiry. These authentic commitments may be written first but they are most likely to be sustained when they are read aloud with some ceremony, to cement them in memory and bring courage and conviction to ongoing practice. Inquiry team members can be witnesses to each other, affirming the growth that has occurred and planning to support one another to maintain commitments through obstacles. This is a phase that emphasizes celebration of learning rather than the reflective challenge that can be offered by critical friends. However, challenge occurs when inquiry team members identify remaining questions or newly discovered incongruities between beliefs and practices.

In the spirit of systems thinking as well as deepening spirals of inquiry, guiding questions bring participants back to the wholeness vision of the first meeting, asking how their sense of possibility may have expanded. Participants consider whether they are ready to invite others to join them in a new cycle of inquiry. The team celebrates together and makes plans to post the pages of the professional inquiry platform template, complete with notes summarizing conversations, to make the learning of this team accessible to colleagues and visitors.

\section{Informed But Not Limited by Action Research Traditions}

The rich scholarly tradition of action research informs our approach to professional inquiry. Reason and Bradbury (2008) described communities of inquiry "that engage in...systematic cycles of action and reflection: in action phases coresearchers test practices and gather evidence; in reflection stages they make sense together and plan further actions" (p. 1). However, we believe the term professional inquiry has more power to revive curiosity and establish a learning culture among educators. Our preferred term puts ownership of learning squarely within the realm of educators' professional activity and leaves a broader scope for investigating meaningful topics in meaningful ways. Tensions that complicate participatory action research, such as the insistence on full participation of co-researchers, the dual purpose of generating knowledge and improving the social condition (Greenwood \& Levin, 2006), or emphasis on action before or after reflection, need not limit professional inquiry options. Although students may be participants in professional inquiry, it is not essential: unlike participative action research (Reason \& Bradbury, 2008; Greenwood \& Levin, 2006), empowerment of a community may focus on the 
capacities of educators themselves, not necessarily on the group they will empower through improved strategies congruent with current and credible beliefs. Similarly, improvement of the social condition may occur when professional action and reflection improve the quality and equity of learning opportunities but a technical focus to improve instructional skills in alignment with expanding vision is also legitimate. Finally, professional inquiry may have a broader range of forms, including an action base, as outlined in our platform, or an analytical base, in which educators review and reflect on existing data to recommend a course of action. As described in Timperley's (2005) criteria, the key to professional inquiry is not in a narrow definition of the process but in the integration of practice, understanding, and values that constitutes learning about how to achieve desired results in classrooms.

\section{Situating Professional Inquiry Within School Improvement}

An environment of increasing anxiety around the ability of schools to prepare children for an unknown future, heightened with annual reports of international educational rankings (Fink, 2008), has been detailed in school improvement literature (Anderson, 2000; Harris \& Chrispeels, 2006; Jacob, 2010; Ungerleider, 2003). Schools for the $21^{\text {st }}$ Century are tasked with preparing children to become lifelong learners, creative and critical thinkers, collaborative team members, and inquisitive and democratic citizens (Canadian Council on Learning, 2010; Jacob, 2010; New London Group, 1996). Within this framework, teachers' roles have shifted significantly. Teachers are no longer seen as providers of static knowledge but as facilitators of information and resources for students' own inquiries through meaningful learning opportunities.

School improvement literature reinforces the importance of teacher learning to enhance student achievement (Timperley, 2005; Muijs \& Harris, 2006). Increasingly, professional learning is becoming connected to concepts of teacher leadership (Muijs \& Harris, 2006; Reeves, 2006). Similarly, teacher leadership is being seen as a foundation for successful school improvement (Lieberman \& Miller, 2004; Muijs \& Harris, 2006; Reeves, 2006). We argue that missing from the research is recognition of the importance of social symmetry-the opportunity for teachers to experience, for themselves, the inquiry opportunities they are expected to provide for students. A renewed emphasis on organizing schools as learning communities (Mitchell \& Sackney, 2009; Crespo, 2008) provides a theoretical forum for placing teacher learning, particular learning through inquiry, at the core of school improvement initiatives. 
In her work with the Innovation Unit out of the UK, Valerie Hannon highlights the need for school transformation based in practitioner-led innovations, particularly because of the historically slow rate of change through school improvement initiatives. She has argued that changes needed to develop a $21^{\text {st }}$ century model of education to prepare children for the fast pace of change in a world of dwindling resources require a new way of thinking about school improvement. Rather than tinkering around the edges of existing school practices, Hannon suggested schools search for "next practice" through practitioner inquiry projects (2009, p. 24).

\section{Unresolved Issues}

In this section, we highlight a few of the unresolved issues that intrigue us. First, there is a tension between the self-renewing purpose of a learning community and our social symmetry argument, which may be seen as an instrumental purpose for professional learning, to improve student learning narrowly defined as improved test scores. Mitchell and Sackney's $(2000,2009)$ conception of learning communities is unique in that it acknowledges the intrinsic value of educators, beyond their role in improving student achievement. From this position, healthy social conditions in the professional workplace are valued as an end in itself, not merely as an end to a means. However, we do see student learning as the essential purpose of schools in a democracy and we wonder how we can hold this sense of organizational purpose in tandem with a non-instrumental respect for educators as human beings.

We see an irony in the tension between standards and standardization and paradox in the notion of ownership without financial control of scarce resources. Standards-based curricula have made it possible for educators to use benchmarks to assess student progress, as in use of the British Columbia Performance Standards, which fuels the evidence-based inquiries sponsored by the Network of Performance Based Schools. However, in our conception of ownership of learning, which we see as compatible with deep engagement as defined for Learning Futures schools, standardization is the enemy of engagement and curiosity. Finally, we question our own advocacy of ownership of learning: How can educators truly own their learning when professional development is funded by school districts and targeted to improve perceived system deficits? For each project, we wonder at what point organizational meaning and personal meaning will connect to create a healthy life and learning sustaining ecology? (Fullan, 2007; Mitchell \& Sackney, 2009) 
These are just a few of the tensions that remain, for us, unresolved, but with the potential to affect the design and delivery of future professional inquiry projects. We have tried to reduce ambiguity and confusion for those new to inquiry with a scaffolding process that is clear and purposeful. However, the story of trial and error in the development of our platform is largely untold. We urge readers not to assume that the process appeared effortlessly, without its own deepening spiral of experimentation, reflection, and revision that continued through several projects over a period of years.

\section{Inquiry for Ownership: Personal Meaning in Professional Learning}

The design of the professional inquiry platform provides a practical scaffold for the creative tension needed to shift schools toward Hannon's (2009) next practice and Mitchell and Sackney's (2009) sustainable learning communities. Both of these school improvement contributions assume that teachers need to move toward the mystery of learning themselves in order to create transformative changes in the students' educational experiences. We offer the inquiry platform as a supported opportunity for building skills to enact vision, as in valuable single loop learning; and to facilitate transformative, double loop learning occasionally when existing mental models are incongruent with research, theory, or student responses. Under the guidance of a skilled and knowledgeable facilitator, our professional inquiry platform has been shown to generate the creative tension necessary for bridging space between perceived reality and desired future possibilities, providing teachers and school leaders a way to engage meaningfully with the mystery of learning in their everyday professional lives.

We continue to challenge ourselves to engage more deeply with the phases of the inquiry platform, as we work with educators, pre-service teachers, and fellow scholars to refine our model. In writing this paper, we have discovered opportunity for further research in designing and applying assessment tools for the professional inquiry platform and for projects that follow this design. We plan to synthesize a set of criteria from the work of Timperley (2005) and others on effective teacher learning, with an eye to the patterns of deep engagement that are emerging in the Learning Futures study (Paul Hamlyn Foundation, About page). 
A deep engagement in learning is required for shifting mindsets, beliefs, and practices - shifts that are necessary for achieving the student learning goals of $21^{\text {st }}$ century education. As participants in our inquiry teams have engaged in the four phases of this inquiry platform, they have sharpened the skills that prevent grand visions from disintegrating into cynicism. With the help of inspiring authors and professional colleagues as critical friends, the shadows of hidden beliefs have come to light for conscious revision. Within developing cultures of inquiry, educators have come to identify incongruence between practice and beliefs as opportunities for cycles of action and reflection. As they continue to inquire with their colleagues in deepening spirals, we believe they will strengthen the integrity of their craft by aligning practice more closely with beliefs. This deep engagement in learning-the integration of practice, understanding, and values that constitutes learning about how to achieve desired results in classrooms - is at the heart of school transformation and is made meaningful for educators as they own their learning through professional inquiry.

\section{References}

Alberta Learning. (2004). Focus on inquiry: $A$ teacher's guide to implementing inquirybased learning. Retrieved January 12,2011, from http://education.alberta.ca/media/ 313361/focusoninquiry.pdf

Anderson, K.D. (2000). School improvement and school reform in Canada...Whose perspective is it? Ways Towards Quality in Education. Conference Proceedings, Brdo pri Kranju, Slovenia, College of Management in Koper. Retrieved October 11, 2010 from http://www2.fmkp.si/zalozba/ ISBN/961-6268-47-3/069-085.pdf

Argyris, C., \& Schon, D. (1978). Organizational learning: A theory of action perspective. Boston: Addison-Wesley.

Black, P., \& Wiliam, D. (1998). Inside the black box: Raising standards through classroom assessment. PHI Delta Kappan (1-12). Retrieved May 2, 2011, from http://www. easlinstitute.org/wp-content/uploads/ Inside\%20the\%20black\%20box.pdf
Brown, W. (2004). Building a learning community through restitution: A case study. Unpublished doctoral dissertation, University of Saskatchewan, Canada.

Brown, W. (2007). ACT: Action circles for teaching. Workshop presented at the annual meeting of the Society for Teaching and Learning in Higher Education (STLHE), Edmonton, Canada. June 15, 2007.

Brown, W., Klein, H., \& Lapadat, J. (2008). Student reports in the digital age: An invitation to classroom inquiry on controlled research. Networks Online Journal of Teacher Research 11(9), 1-11.

Brown, W., \& Lapadat, J. (n.d.). The Learners' Platform Network. Retrieved May 9, 2011, from www.learnersplatform.ca

Canadian Council on Learning. (2010). 2009-2010, State of Learning in Canada: A year in review. Executive summary. Retrieved October 11, 2010, from http:// www.ccl-cca.ca/pdfs/SOLR/2010/ SOLR-2010ExecSum-FINAL-E.pdf. 
Carr, W., \& Kemmis, S. (1986). Becoming critical: Education, knowledge and action research. Philadelphia: Falmer Press.

Crespo, M. (2008). Leadership and conceptions of organization: Contours of the distributed perspective. LEARNing Landscapes, $1(2), 55-69$.

Davy, A., \& Brown. (2007). Turning show'n'tell into democratic dialogue. Networks Online Journal of Teacher Research, 9(1), 1-13.

Dufour, R., \& Eaker, R. (1998). Professional learning communities: Best practices for enhancing student achievement. Bloomington, IN: Solution Tree.

Fink, D. (2008). Schools as centres of change not centres of blame: Constructing bridges between policy and practice. LEARNing Landscapes, 1(2), 99-111.

Fullan, M. (2007). The new meaning of educational change (4th ed.). New York: Teachers College Press.

Greenwood, D., \& Levin, M. (2006). Introduction to action research: social research for social change (2nd ed.). Thousand Oaks, CA: Sage.

Hannon, V. (2009). The search for Next Practice: A UK approach to innovation in schools. Education Canada, 49(4), 24-27.

Hannon, V., \& Mackay, T. (2010, November). Developing the $B C$ learning agenda: Innovation and improvement. Keynote address at the BC School Superintendents Annual Fall Conference: Personalized Learning in the 21st Century: From Vision to Action. Victoria, BC, Canada.

Harris, A., \& Chrispeels, J.H. (Eds.). (2006). Improving schools and educational systems: International perspectives. London: Routledge.

Hattie, J. (2008). Visible learning: A synthesis of over 800 meta-analyses relating to achievement. New York: Routledge.

Jacob, H. (Ed.). (2010). Curriculum 21: Essential education for a changing world. Alexandria, VA: Association for Supervision and Curriculum Development.

Kaser, L., \& Halbert, J. (n.d.). Network of Performance Based Schools website. Retrieved May 9, 2011, from http:// www.npbs.ca/
Kaser, L., \& Halbert, J. (2009). Leadership mindsets: Innovation and learning in the transformation of schools. New York: Routledge.

Koehn, D. (2011). A spiral of inquiry: Metacognitive reflection for all learners. Paper presented at the International Congress for School Effectiveness and School Improvement (ICSEI), Limassol, Cyprus, January $4-7$.

Kotter, J., \& Cohen, D. (2002). The heart of change: Real life stories of how people change their organizations. Boston: Harvard Business Press.

Lieberman, A., \& Miller, L. (2004). Teacher leadership. San Francisco: Wiley \& Sons.

Mitchell, C., \& Sackney, L. (2000). Profound improvement: Building capacity for a learning community. Lisse, The Netherlands: Swets \& Zeitlinger.

Mitchell, C., \& Sackney, L. (2009). Sustainable improvement: Building learning communities that endure. Rotterdam, The Netherlands: Sense.

Muijs, D., \& Harris, A. (2006). Teacher led school improvement: Teacher leadership in the UK. Teaching \& Teacher Education: An International Journal of Research and Studies, 22(8), 961-972.

New London Group. (1996). A pedagogy of multiliteracies: Designing social futures. Harvard Educational Review, 66, 60-92.

Paul Hamlyn Foundation. (n.d.). Learning futures: Engaging students, inspiring schools. Retrieved May 2, 2011, from http:// www.learningfutures.org/

Philips, G. (1996). The school-classroom culture audit: Transformational instrument and process. Issaquah, WA: National School Improvement, Inc.

Reason, P., \& Bradbury, H. (Eds.). (2008). Introduction. The Sage handbook of action research: Participative inquiry and practice (pp. 1-10). United States: Sage.

Reeves, D. (2006). The learning leader: How to focus school improvement for better results. Alexandria, VA: Association for supervision and curriculum development. 
Robinson, V. (2008). The impact of leadership on student outcomes: Making sense of the evidence. Melbourne: Australian Council for Educational Research. Retrieved January 12,2011, from http://research.acer.edu.au/ research_conference_2007/5/

Sagor, R. (2000). Guiding school improvement with action research. Alexandria, VA: ASCD.

Senge, P. (2007). The fifth discipline: The art and practice of the learning organization (revised edition). Doubleday: New York.

Senge, P., Cambron-McCabe, N., Lucas, T., \& Smith, B. (2000). Schools that learn: A fifth discipline field book for educators, parents, and everyone who cares about education. New York: Crown Business.
Silverstein, S. (1964). Giving tree. New York: Harper \& Row.

Timperley, H. (2005). Distributed leadership: Developing theory from practice. Journal of Curriculum Studies, 37(4), 395-420.

Ungerleider, C. (2003). Failing our kids: How we are ruining our public schools. Toronto, ON: McClelland \& Stewart.

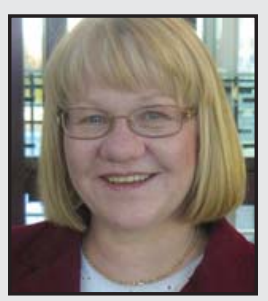

Willow Brown, a classroom teacher for 16 years, received a master's from the University of Alaska Southeast and a doctorate in school improvement from the University of Saskatchewan. She now coordinates a master's program for school leaders at the University of Northern British Columbia. Her research interests include assessment and professional learning community development. Currently, she is interested in applying her experience with action research to develop new understandings of professional inquiry.

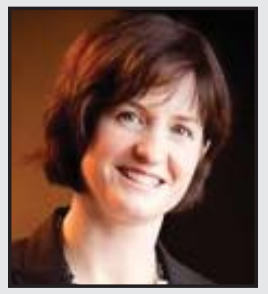

Sabre Cherkowski is an assistant professor in educational leadership at the University of British Columbia Okanagan where she also serves as coordinator of the master's program in educational leadership. Her research interests include professional learning communities, teacher commitment, and teacher leadership. She is currently exploring the role of coaching as mentorship for increased professional learning in schools. 